\title{
Location of uronic acid group in Japanese cedar and Japanese beech wood cell walls as evaluated by the influences of minerals on thermal reactivity
}

\author{
Jiawei Wang, Eiji Minami and Haruo Kawamoto*
}

\begin{abstract}
The thermal reactivities of cellulose and hemicellulose are significantly different in cell walls when compared with isolated components and differ in Japanese cedar (softwood) and Japanese beech (hardwood). Uronic acid bound to xylan promotes the thermal degradation of cellulose and hemicellulose, and its effect is different depending on the form of free acid (acting as an acid catalyst) or metal uronate (acting as a base catalyst). We evaluated the location of uronic acid in the cell wall by identifying the components affected by demineralization in pyrolysis of cedar and beech wood. The thermal reactivities of xylan and glucomannan in beech were changed by demineralization, but in cedar, glucomannan and cellulose reactivities were changed. Therefore, the location of uronic acid in the cell wall was established and differed between cedar and beech; close to glucomannan and xylan in beech, but close to glucomannan and cellulose in cedar. Such information is important for understanding the ultrastructure and pyrolysis behavior of softwood and hardwood cell walls.
\end{abstract}

Keywords: Pyrolysis, Wood cell wall, Location of uronic acid, Softwood, Hardwood

\section{Introduction}

Wood has a heterogeneous cell wall structure consisting of nano-sized cellulose microfibrils surrounded by the hemicellulose-lignin matrix. The types and contents of hemicellulose are different depending on the plant species. In hardwood, xylan is dominant (10-30 $w t \%)$ and the content of glucomannan is quite small (3-5 wt\%), while softwood contains more glucomannan (14-25 wt\%) and less xylan (5-15 wt\%) [1]. The assembly of hemicelluloses in the matrix has been studied and is suggested to be different in the cell walls of softwoods and hardwoods. Glucomannan has been reported to bind to the surface of cellulose microfibrils in softwood [2-5], while xylan associates with cellulose in hardwood

*Correspondence: kawamoto@energy.kyoto-u.ac.jp Graduate School of Energy Science, Kyoto University, Yoshida-honmachi, Sakyo-ku, Kyoto 606-8501, Japan
[6-9]. Recently, however, xylan is also reported to bind to cellulose in spruce, which is a softwood [10]. Thus, the location of hemicellulose in the cell wall has not been completely clarified. Such ultrastructure of cell walls may affect the thermal degradation reactivity of the component polysaccharides.

Thermogravimetric (TG) analysis is frequently used to identify softwood and hardwood species [11-14]. Crystalline cellulose is more thermally stable than isolated hemicellulose, which has amorphous properties, so these components are thought to decompose over different temperature ranges. Pyrolysis of hardwoods occurs in two ranges, depending on the pyrolysis temperature, and gives a characteristic derivative thermogravimetric (DTG) curve with a clear shoulder in the lower temperature range. This shoulder is generally attributed to the degradation of xylan, because isolated xylan is more reactive than glucomannan or cellulose. On the contrary, no 
clear shoulders are observed on the DTG curves of softwoods. This is thought to be caused by the high content of glucomannan in softwood, which is less reactive than xylan [15-18].

Our previous study using Japanese cedar (Cryptomeria japonica, a softwood) and Japanese beech (Fagus crenata, a hardwood) [19] questioned the above interpretation of the DTG curves. Xylan was remarkably stable against pyrolysis in both wood cell walls as compared to isolated xylan and exhibited similar reactivity to glucomannan in cedar. In contrast, glucomannan in beech wood was quite reactive and decomposed at a lower temperature than xylan, which is the opposite of that observed in isolated samples. Therefore, the pyrolysis behavior of hemicellulose in wood cannot be explained by the thermal reactivity of isolated hemicelluloses. The difference in DTG curves between cedar and beech wood was explained by the different thermal decomposition behaviors of cellulose, which was synchronized with hemicellulose degradation in cedar, but was independent in beech.

The 4-O-methyl-D-glucuronic acid (4-O-MeGlcA) bound to the xylose chain of xylan and its salt act as acid and base catalysts, respectively, during pyrolysis, which can promote the thermal degradation of nearby components. This effect has been confirmed by comparing the thermal reactivities between isolated xylans containing the $\mathrm{Na}$ salt of 4-O-MeGlcA and demineralized sample with the free carboxylic acid [20]. Given that the catalytic effects of the free acid and the metal salt are different, we considered that the location of 4-O-MeGlcA can be established by identifying the components for which the reactivity changes with demineralization. Most of the 4-O-MeGlcA in wood are thought to be present as metal salts or esters with lignin [21-24]. Asmadi et al. [21] reported a good linear relationship between the amounts of metal cations and uronic acids using 5 softwood and 5 hardwood species and they concluded that most of the metal cations bind to uronic acid to form salts. Metal cations can be removed from wood by washing with a weakly acidic solution (Fig. 1).

In the present study, the pyrolytic reactivity of xylan, glucomannan, and cellulose in cedar and beech wood and their demineralized samples were evaluated from

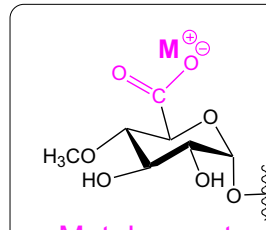

Metal uronate

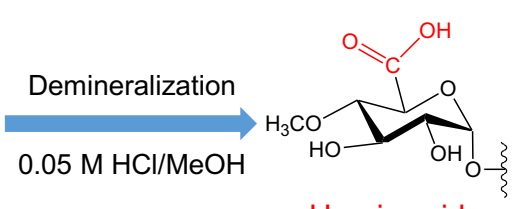

Uronic acid
Fig. 1 Metal uronate changes to uronic acid by treatment with dilute acidic solution the recovery of hydrolyzable sugar after heating to $220-380{ }^{\circ} \mathrm{C}$ at a heating rate of $10{ }^{\circ} \mathrm{C} / \mathrm{min}$ under $\mathrm{N}_{2}$ flow without a holding period. The TG and DTG curves were measured at the same heating rate of $10{ }^{\circ} \mathrm{C} / \mathrm{min}$ under $\mathrm{N}_{2}$ flow and compared with the reactivity results to explain the weight-loss behavior in terms of the degradation of hemicellulose and cellulose. The location of 4-O-MeGlcA in beech and cedar wood is discussed based on the present results.

\section{Experimental \\ Materials}

Wood flour (passing 80 mesh) prepared from the sapwood of Japanese cedar and Japanese beech wood was extracted with acetone using a Soxhlet extractor, and then dried in an oven at $105{ }^{\circ} \mathrm{C}$ for $24 \mathrm{~h}$. Following the process of wood demineralization [21, 25], wood flour $(1 \mathrm{~g})$ was suspended in a solution of $0.05 \mathrm{M} \mathrm{HCl}$ in methanol $(30 \mathrm{~mL})$ and stirred for $24 \mathrm{~h}$ at room temperature. After filtration, the wood flour was washed with distilled water several times until the supernatant became neutral and the residue was dried in an oven at $105{ }^{\circ} \mathrm{C}$ for $24 \mathrm{~h}$. The process was repeated twice to ensure the complete removal of metal cations. Complete removal of minerals by this treatment was confirmed with the no residue remaining after incineration of the demineralized sample in air at $600{ }^{\circ} \mathrm{C}$ for $2 \mathrm{~h}$. The $0.05 \mathrm{M} \mathrm{HCl} / \mathrm{MeOH}$ may penetrate into cell walls and remove metal cations from uronate salts. Commercially available beech wood xylan (Megazyme, Wicklow, Ireland) and konjac glucomannan (Carbosynth, Berkshire, United Kingdom) were used as isolated hemicelluloses [19].

The characterizations of original and demineralized wood samples are described in previous reports [21, 26]. The metal cation composition of the original wood is summarized in Table 1 [26]. $\mathrm{K}^{+}$and $\mathrm{Ca}^{2+}$ were the major components, and lesser amounts of $\mathrm{Mg}^{2+}$ and $\mathrm{Na}^{+}$were also present, along with low amounts of $\mathrm{Fe}$ and $\mathrm{Cu}$ cations. Although the contents of metal cations in the demineralized wood samples were not determined, previous report of our laboratory shows the reduction rates using

Table 1 Metal cation composition of original Japanese cedar and Japanese beech wood

Content/ppm

\begin{tabular}{lllllc}
\hline & $\mathbf{N a}^{+}$ & $\mathbf{K}^{+}$ & $\mathbf{M g}^{\mathbf{2}}$ & $\mathbf{C a}^{\mathbf{2 +}}$ & Others \\
\hline Cedar & 47 & 400 & 100 & 600 & 6 \\
Beech & 85 & 830 & 300 & 770 & 18
\end{tabular}

Others: $\mathrm{Cu}, \mathrm{Fe}$

Data from Asmadi et al. [26] 
the similar demineralization procedure: content (ppm) 1100-15 (K), 100-42 (Na), 780-64 (Ca), and 280-3.8 $(\mathrm{Mg})$ for Japanese cedar wood [25].

\section{TG analysis}

TG analysis was conducted using a TGA-50 instrument (Shimadzu, Kyoto, Japan). Wood flour (1 mg) was placed into a platinum pan and heated from room temperature to $800{ }^{\circ} \mathrm{C}$ at a heating rate of $10{ }^{\circ} \mathrm{C} / \mathrm{min}$ under a $\mathrm{N}_{2}$ flow of $10 \mathrm{~mL} / \mathrm{min}$ (purity: 99.9998\%, Japan Fine Products, Mie, Japan). $\mathrm{N}_{2}$ was first passed through a deoxygenation column (GL Sciences, Tokyo, Japan) to remove any oxygen contamination.

\section{Pyrolysis}

The experimental setup used in this research is illustrated in Fig. 2, and the experimental procedure is described in detail in a previous report [19]. A quartz glass tube (internal diameter $15 \mathrm{~mm}$, length $400 \mathrm{~mm}$, wall thickness $1.5 \mathrm{~mm}$ ) was placed in an electric furnace (Asahi-Rika Seisakusho, Chiba, Japan). For each experiment, the sample $(20 \mathrm{mg}$ ) was placed in a ceramic boat (As One, Osaka, Japan), which was then placed in the center of the glass tube. Thereafter, the air inside the glass tube was displaced by a $\mathrm{N}_{2}$ flow $(100 \mathrm{~mL} / \mathrm{min})$ for 5 min using a mass flow controller (SEC-400MK3; Horiba, Kyoto, Japan). The sample was subjected to heat treatment at a set temperature $\left(220-380{ }^{\circ} \mathrm{C}\right.$, at $20{ }^{\circ} \mathrm{C}$ intervals), at a heating rate of $10{ }^{\circ} \mathrm{C} / \mathrm{min}$, which was the same heating rate used for TG analysis. The sample temperature was directly measured during the pyrolysis experiment by contacting the tip of a fine thermocouple $(0.25 \mathrm{~mm}$ in diameter, type $\mathrm{K}$, SHINNETSU, Ibaraki, Japan) to the sample and the data were recorded with a thermologger (AM-8000, Anritsu, Kanagawa, Japan). When the temperature reached the designated temperature, the cover of the electric furnace was opened, and the glass tube was immediately cooled to room temperature under a flow of air.

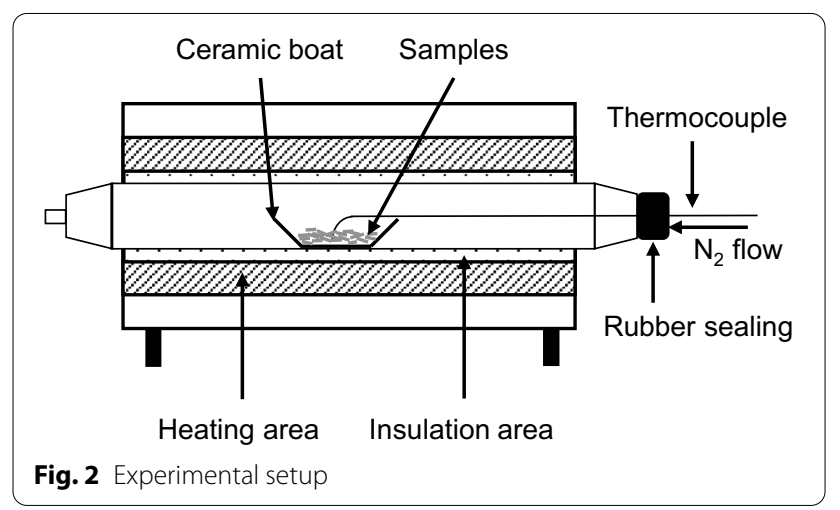

Pyrolysis was repeated several times for each condition to confirm the reproducibility. The data are shown as average values. The amounts of unreacted hemicellulose and cellulose remaining in heat-treated wood samples were evaluated by the yields of hydrolyzable sugars.

\section{Determination of hydrolyzable sugars}

Hydrolyzable sugars were determined according to the procedure described in a previous report [19]. Acid hydrolysis was used to convert cellulose in the heattreated wood into glucose [27]. Hydrolysis was performed in $0.3 \mathrm{~mL}$ of $72 \% \mathrm{H}_{2} \mathrm{SO}_{4}$ solution at $30{ }^{\circ} \mathrm{C}$ for $1 \mathrm{~h}$. The mixture was diluted with $8.4 \mathrm{~mL}$ of water and heated to $120^{\circ} \mathrm{C}$ (in an autoclave) for $1 \mathrm{~h}$. After neutralization by elution on a Dionex OnGuard II A cartridge (Thermo Fisher Scientific, Waltham, MA, USA), the glucose yield was determined by high-performance anion-exchange chromatography using a Prominence chromatograph (Shimadzu, Kyoto, Japan) equipped with an electrochemical detector (Decade Elite, Antec Scientific, Zoeterwoude, Netherlands). The separation conditions were: column, CarboPac PA1 $(4 \times 250 \mathrm{~mm})$; eluent, $85 \%$ distilled water $/ 15 \% 0.2 \mathrm{M} \mathrm{NaOH}$; column oven temperature, $35^{\circ} \mathrm{C}$.

Mild methanolysis was conducted to determine the yields of the hydrolyzable sugars from hemicellulose, pectin, and uronic acid as methyl glycosides [21, 28-30]. Methanolysis was performed in $2 \mathrm{M} \mathrm{HCl}$ in methanol (KOKUSAN CHEMICAL, Tokyo, Japan) at $60{ }^{\circ} \mathrm{C}$ for $16 \mathrm{~h}$. After neutralization with pyridine, the methanolysis products were trimethylsilylated with pyridine, hexamethyldisilazane, and trimethylchlorosilane at $60{ }^{\circ} \mathrm{C}$ for $30 \mathrm{~min}$. The products were analyzed by gas chromatography-mass spectrometry (QP-2010 Ultra; Shimadzu, Kyoto, Japan). The instrumental conditions were: column, CPSil 8CB $(30 \mathrm{~m} \times 0.25 \mathrm{~mm}$ i.d.; Agilent, Santa Clara, CA, USA); injector temperature, $260{ }^{\circ} \mathrm{C}$; split ratio, 1:50; column temperature, $100{ }^{\circ} \mathrm{C}(2 \mathrm{~min}), 4^{\circ} \mathrm{C} / \mathrm{min}$ to $220{ }^{\circ} \mathrm{C}, 220{ }^{\circ} \mathrm{C}(2 \mathrm{~min}), 15{ }^{\circ} \mathrm{C} / \mathrm{min}$ to $300{ }^{\circ} \mathrm{C}, 300{ }^{\circ} \mathrm{C}$ (2 min); carrier gas, helium. The signals originating from hemicellulose and 4-O-MeGlcA were assigned based on the associated mass spectra and retention times, as compared with literature data [28, 29, 31, 32].

\section{Results and discussion TG/DTG profile}

Figure 3 illustrates the TG/DTG profiles measured for the original and demineralized cedar and beech wood samples. The different DTG curves in shape of the original cedar and beech wood samples are maintained after the demineralization treatment; a shoulder is clearly visible in the beech DTG curves, but not in the cedar DTG curves. This difference were explained in our previous 


\section{a Cedar}

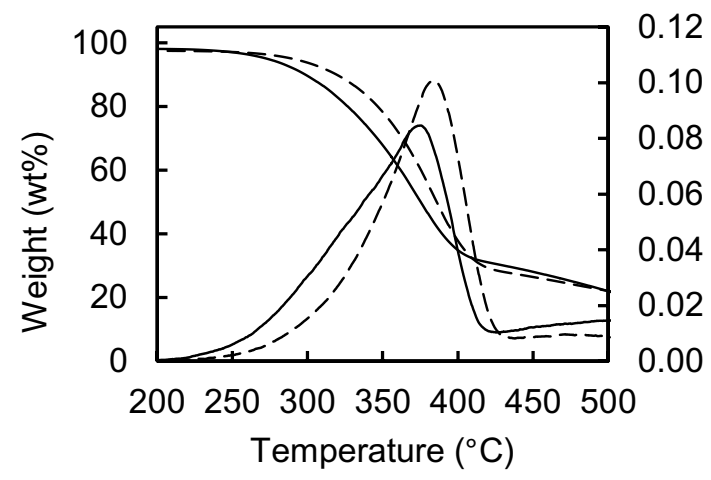

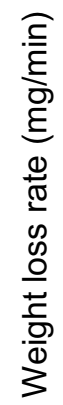

b Beech

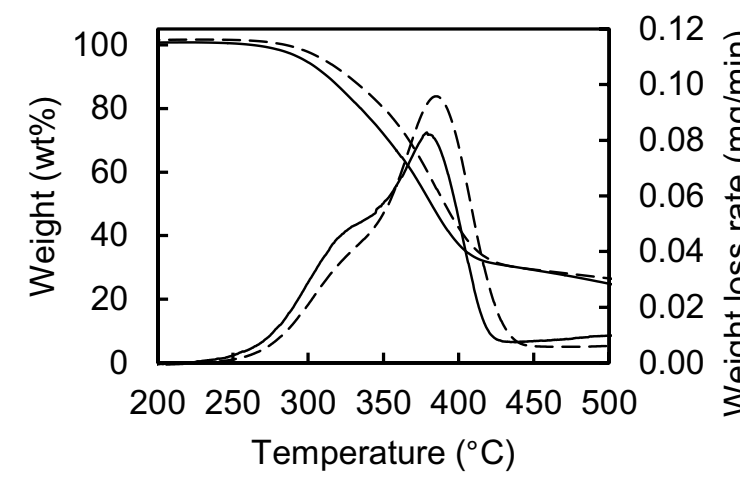

Fig. 3 TG/DTG curves obtained for original ( - ) and demineralized (---) Japanese cedar and Japanese beech wood

study [19] in terms of the different thermal degradation behaviors of hemicellulose and cellulose in wood. Hemicellulose and cellulose degrade independently in beech wood, but degrade together in cedar wood. Thus, such characteristic behaviors were not changed by demineralization. However, for both wood types, the TG/DTG curves shifted to the higher temperature side by demineralization, indicating that some components of wood are stabilized by changing the 4-O-MeGlcA moiety from metal uronate to free acid. The temperature range in which the weight loss of cedar wood occurred was narrowed by demineralization, which was different from the behavior of beech wood.

\section{Reactivity of hemicellulose and cellulose in wood}

To understand the decomposition of hemicellulose and cellulose during pyrolysis, the hydrolyzable sugar was recovered from wood samples that were pyrolyzed at each temperature between 220 and $380{ }^{\circ} \mathrm{C}$. Using the same heating rate of $10^{\circ} \mathrm{C} / \mathrm{min}$ to $\mathrm{TG}$ analysis, the results of TG analysis can be discussed in terms of the degradation of hemicellulose and cellulose. The recovery of mannose indicates the stability of glucomannan, because all determined mannose is derived from the glucomannan remaining in the pyrolyzed wood. Xylose recovery shows the stability of xylan for the same reason. However, glucomannan also contains glucose as a constituent sugar, so some adjustment is required to assess the reactivity of cellulose. The amount of cellulose-derived glucose was determined by subtracting the amount of glucomannan-derived glucose, assuming that the sugar composition of glucomannan is mannose: glucose $=3: 1$ $[33,34]$ and both units have the same thermal degradation reactivity.

The remaining amounts of xylan, glucomannan, and cellulose in pyrolyzed wood, which was determined from the recovery of hydrolyzable sugar and the composition of the original and demineralized wood, are plotted against the pyrolysis temperature in Fig. 4 and compared with the DTG curves. Weight loss caused by the thermal degradation of lignin was also involved in these DTG curves, but the contribution was small because of the properties of lignin, which tends to be converted to char [35-37].

Although the effect of demineralization on the pyrolytic reactivity of cellulose in beech wood was very limited, the cellulose in cedar wood was stabilized by demineralization. For cedar hemicellulose, glucomannan was stabilized, but the xylan reactivity was not affected. These results are surprising because the 4-O-MeGlcA moiety is bound to xylan. Based on these results, we concluded that the 4-O-MeGlcA is close to glucomannan and cellulose in cedar instead of the xylose units of xylan. Consequently, the shift of the TG/DTG curves of cedar wood by demineralization is explained by the change in reactivity of cellulose and glucomannan. The narrowing of the temperature range in which cellulose and glucomannan in cedar wood decompose is consistent with the abovementioned trend in the TG/DTG curves of cedar wood.

The influence of demineralization of beech wood were very different from that of cedar wood. By demineralization, the degradation temperature of xylan in beech wood was shifted to lower temperature, but the influence on the reactivity of cellulose was small. Therefore, changes in the TG/DTG curve of beech wood are mostly explained by changes in the reactivity of xylan in the temperature range of $260-340{ }^{\circ} \mathrm{C}$. This is reasonable because the 4-O-MeGlcA is bound to xylan. Because of its low content, the contribution of glucomannan to the TG/ DTG curve is very small in beech wood.

In Fig. 5, the recovery of xylose, mannose, and 4-O-MeGlcA, normalized as $100 \%$ for untreated samples, is compared with that of isolated glucomannan [19] and xylan [20], which were reported in previous work. These comparisons provide an understanding 


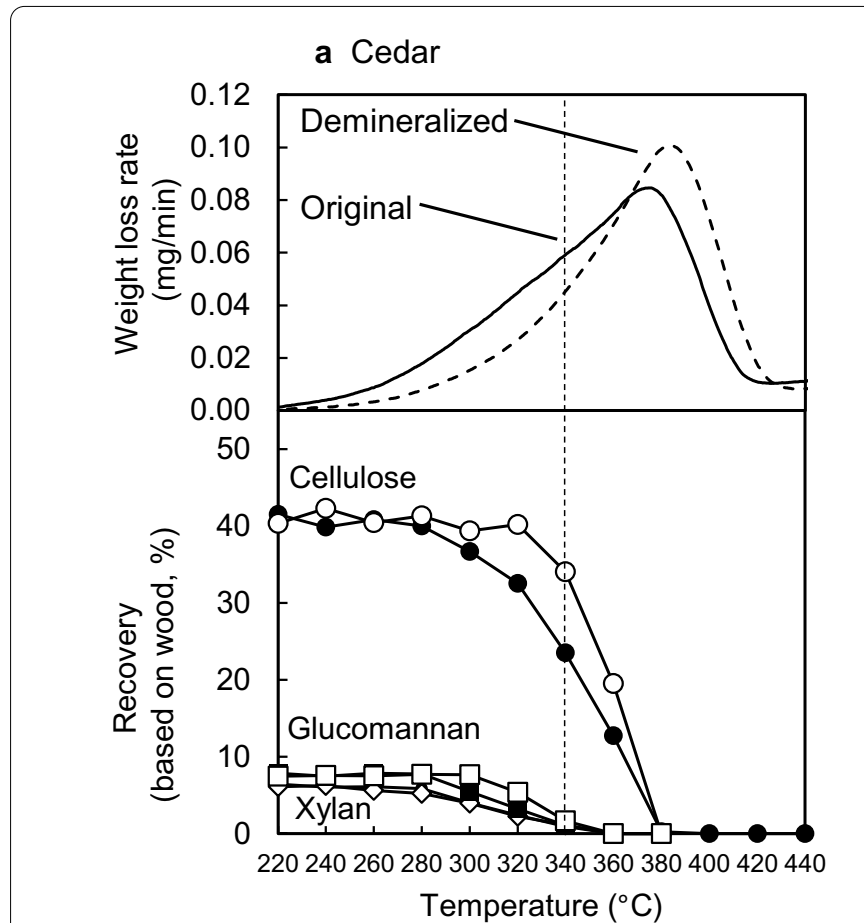

Fig. 4 Comparison of the DTG curves with the recovery ratios of cellulose and glucomannan Japanese cedar and Japanese beech wood

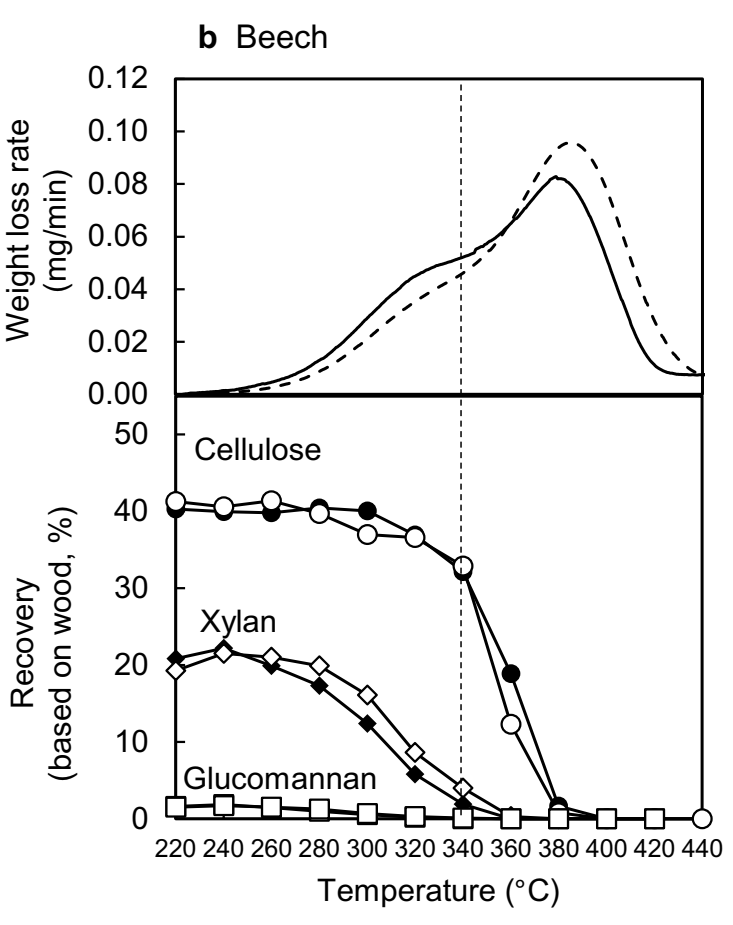

: original, $\bigcirc$ : demineralized), xylan original, $\diamond$ : demineralized) the hydrolyzable sugars in pyrolysis of original and demineralized of the thermal reactivity of xylan, glucomannan, and 4-O-MeGlcA moieties in xylan in wood compared with isolated hemicellulose. The isolated xylan contained a sodium salt of 4-O-MeGlcA, which was converted to a free acid by demineralization [20]. Demineralized konjac glucomannan was not shown, since it does not contain any acidic groups.

The isolated xylan was more reactive than glucomannan because of the influences of 4-O-MeGlcA (acidic) and its sodium salt (basic). As already mentioned, xylan (xylose unit and 4-O-MeGlcA) was remarkably stable in both wood types and exhibited similar reactivity to glucomannan in cedar. This trend was not changed by demineralization in both woods, indicating that minerals contained in wood do not play a critical role in the stabilizing effects of xylan in the cell walls.

The beech xylan was slightly stabilized by demineralization, although the reactivity of cedar xylan did not change. These results indicate that the 4-O-MeGlcA moiety bound to xylan affects the thermal degradation of xylose units in beech, but not in cedar. Although this result is difficult to explain based on our current knowledge, it is possible that the 4-O-MeGlcA of cedar xylan may not have access to the xylose units (for some unknown reason). Nevertheless, these effects of
4-O-MeGlcA are far less than the differences observed in the pyrolysis of wood and isolated xylan.

The glucomannan reactivity was very different for cedar and beech, because the glucomannan in beech wood was more reactive than isolated glucomannan, as described in our previous report [19]. The reactivity in beech was slightly reduced by demineralization, but was still much greater than that in isolated glucomannan. Therefore, it is suggested that the 4-O-MeGlcA is close to glucomannan and affects the thermal reactivity, which may improve the reactivity of glucomannan in beech wood, unlike in cedar.

As described earlier, the cedar glucomannan was stabilized by demineralization, especially in the temperature range of $300-320{ }^{\circ} \mathrm{C}$. This temperature range is close to the range in which the reactivity of 4-O-MeGlcA decreased by demineralization. Although some detail is lacking at this point, it appears that the stabilization of glucomannan may be related to the altered reactivity of the 4-O-MeGlcA. It is suggested that the location of glucomannan in both wood types is close to the 4-O-MeGlcA, but the reactivity is very different in cedar and beech. Accordingly, other factors must be considered to explain these different reactivities.

The reactivity of the 4-O-MeGlcA was different for cedar and beech wood. It was quite stable over the 


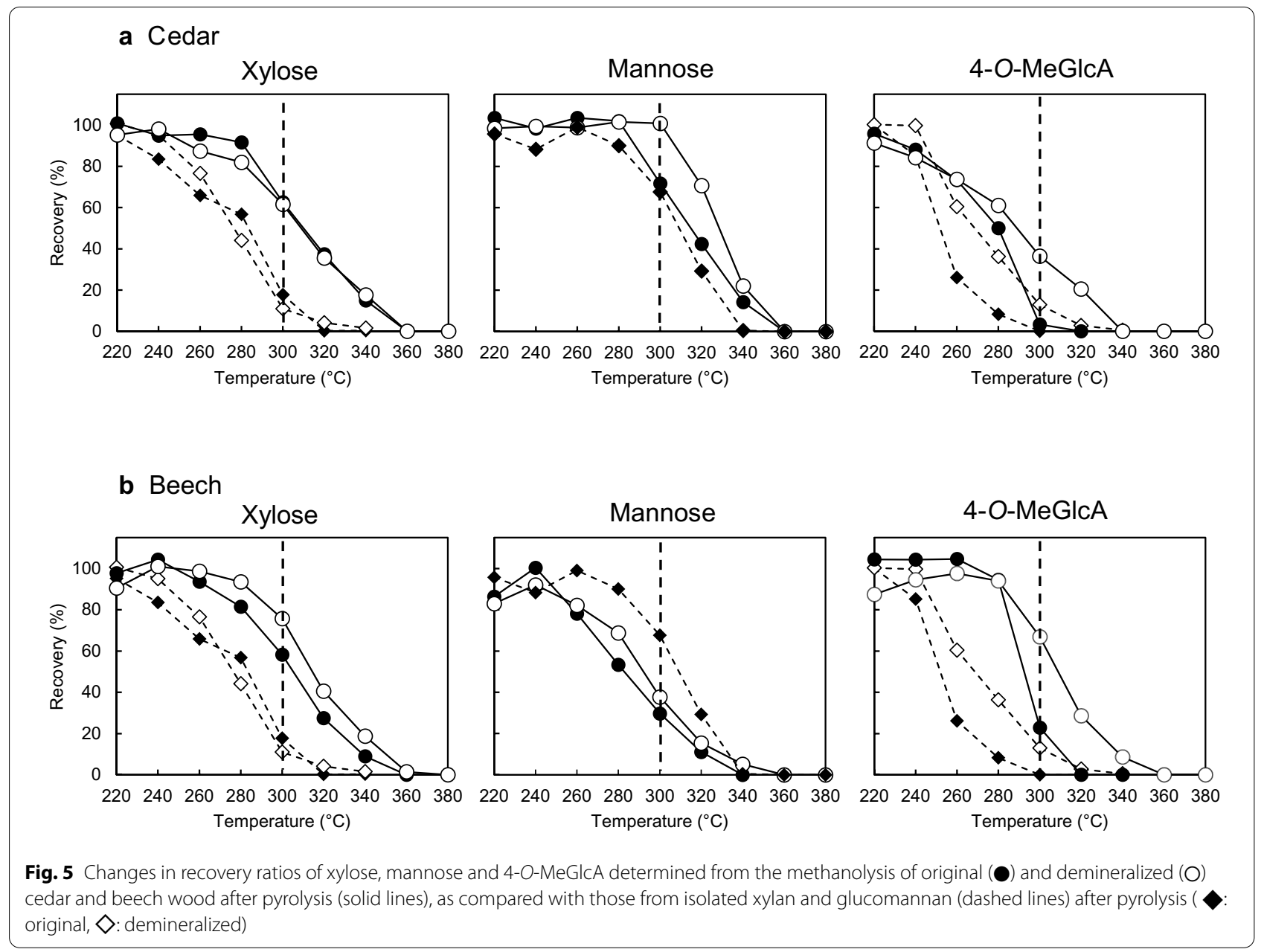

relatively low temperature range of $220-280{ }^{\circ} \mathrm{C}$ in beech, but degraded in cedar. Explanation of these differences is difficult at present, but the environment around the 4-O-MeGlcA in wood is likely to differ between cedar and beech. As described above for cedar wood, by demineralization, the 4-O-MeGlcA in both wood types was stabilized in the temperature range of $300-320^{\circ} \mathrm{C}$.

\section{Location of uronic acid in cellulose and hemicellulose aggregates in cell wall}

The wood cell wall polysaccharides influenced by demineralization are summarized in Table 2. The 4-O-MeGlcA bound to xylan may be near the affected component. The most interesting finding is the effect on cedar wood, indicating that the 4-O-MeGlcA is closer to cellulose and glucomannan. In softwood cell walls, glucomannan is thought to bind strongly to the surface of cellulose microfibrils [2]. If this is true, it cannot explain the effects of demineralization observed in this study. Instead of the previous model, a new model shown in Fig. 6a is proposed to explain the present results. In this model,
Table 2 Summary of the influences of demineralization on thermal reactivities of cellulose, hemicelluloses and uronic acid in pyrolysis of Japanese cedar and Japanese beech wood

\begin{tabular}{lllll}
\hline & Cellulose & Xylan & Glucomannan & Uronic acid \\
\hline Cedar & ++ & nd & ++ & ++ \\
Beech & nd & + & + & ++
\end{tabular}

nd not detected

+ and ++ : degree of stabilization by demineralization

4-O-MeGlcA bound to xylan is placed between cellulose and glucomannan, although the amount of 4-O-MeGlcA is unknown.

The association of xylan with cellulose has been shown to explain the formation of helicoid-type arrays of cellulose microfibrils in the cell wall [7]. Cellulose microfibrils surrounded by xylan can be moved to place helicoid arrays by repulsion between negatively charged 4-O-MeGlcA. Very recently, Terrett et al. 


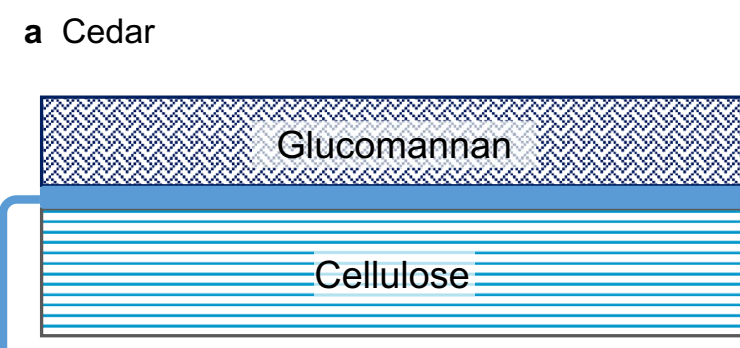

Uronic acid must exist in this area

\section{b Beech}

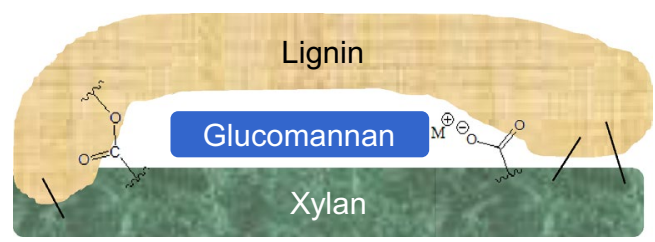

Fig. 6 Location of uronic acid groups in cell walls as proposed for cedar (a) and beech (b) wood based on the present results

studied the polymer interactions in never-dried cell walls of spruce, a softwood, using ${ }^{13} \mathrm{C}$ multidimensional solid-state nuclear magnetic resonance spectroscopy. They proposed a new molecular architecture of softwood, in which both glucomannan and xylan bind to the surface of cellulose microfibrils [10]. This is consistent with the model in Fig. 6a, and these lines of literature information support the current research proposal. As mentioned earlier, however, there are still many unknowns about the thermal reactivity of hemicellulose and cellulose in cedar wood. Lignin may be involved in these unique thermal properties, which we will discuss elsewhere.

Regarding the assembly of beech wood cell walls, the observed influences of demineralization on the reactivity of xylan and glucomannan indicate the close proximity of these components, as illustrated in Fig. 6b. A notable property in beech wood was the significantly improved reactivity of glucomannan, while xylan containing the 4-O-MeGlcA was stabilized. To explain these characteristics, the 4-O-MeGlcA needs to be placed in a specific position in the aggregate. Lignin and lignin-carbohydrate complex linkages such as $\mathrm{C} \gamma$-ester with 4-O-MeGlcA, benzyl ether, and phenyl glycoside are considered to tighten the aggregate structure. This will also be discussed elsewhere.

\section{Conclusions}

The influences of minerals in cedar and beech wood were investigated to understand the location of the 4-O-MeGlcA in wood cell walls and the influences on the pyrolytic reactivity of hemicellulose and cellulose in wood. The following conclusions are obtained:

1. The TG/DTG curves shifted to higher temperature with demineralization treatment. This was caused by changes in the reactivity of cellulose and glucomannan in the case of cedar, but was related to changes in the reactivity of xylan and glucomannan in the case of beech.

2. When compared with the reactivity of isolated hemicellulose, xylan was significantly stabilized in both wood types, but glucomannan was more reactive in beech wood. These trends did not change with demineralization treatment.

3. The effects of demineralization indicated the location of the 4-O-MeGlcA, which was close to glucomannan and cellulose in cedar, but was close to glucomannan and xylan in beech.

4. The cell wall structures of cedar and beech wood were discussed with reference to the arrangement of hemicellulose and cellulose. However, it is considered that the arrangement in cedar wood is complex and many unknowns remain concerning the thermal reactivity of hemicellulose and cellulose.

Abbreviations

TG: Thermogravimetric; DTG: Derivative thermogravimetric; 4-O-MeGICA: 4-O-Methyl-D-glucuronic acid.

\section{Acknowledgements}

We appreciate the assistance of Dr. Mohd Asmadi, Faculty of Chemical and Energy Engineering, Universiti Teknologi Malaysia, for preparing the original wood samples and conducting TG analysis. We thank Austin Schultz, PhD, from Edanz Group (https://en-author-services.edanzgroup.com/ac) for editing a draft of this manuscript.

\section{Authors' contributions}

The experiment, data analysis, and manuscript writing were conducted by JW under the supervision of HK and EM. All the authors read and approved the final manuscript.

\section{Funding}

This work was supported by the Japan Society for the Promotion of Science (Grant Numbers JP16H04954, JP19H03019).

\section{Availability of data and materials}

The datasets used and/or analyzed during the current study are available from the corresponding author on reasonable request.

Ethics approval and consent to participate

Not applicable. 


\section{Consent for publication \\ Not applicable.}

\section{Competing interests}

The authors declare that they have no competing interests.

Received: 23 October 2020 Accepted: 15 December 2020 Published online: 07 January 2021

\section{References}

1. Haraguchi T (1985) Hemicellulose. Wood chemistry. Buneido-shuppan, Tokyo, pp 84-95 (In Japanese)

2. Terashima N, Kitano K, Kojima M, Yoshida M, Yamamoto H, Westermark U (2009) Nanostructural assembly of cellulose, hemicellulose, and lignin in the middle layer of secondary wall of ginkgo tracheid. J Wood Sci 55:409-416

3. Maeda Y, Awano T, Takabe K, Fujita M (2000) Immunolocalization of glucomannans in the cell wall of differentiating tracheids in Chamaecyparis obtusa. Protoplasma 213:148-156

4. Kumagai A, Endo T (2018) Comparison of the surface constitutions of hemicelluloses on lignocellulosic nanofibers prepared from softwood and hardwood. Cellulose 25:3885-3897

5. Åkerholm M, Salmén L (2001) Interactions between wood polymers studied by dynamic FT-IR spectroscopy. Polymer 42:963-969

6. Dammström S, Salmén L, Gatenholm P (2009) On the interactions between cellulose and xylan, a biomimetic simulation of the hardwood cell wall. BioResources 4:3-14

7. Simmons TJ, Mortimer JC, Bernardinelli OD, Pöppler AC, Brown SP, deAzevedo ER, Dupree R, Dupree P (2016) Folding of xylan onto cellulose fibrils in plant cell walls revealed by solid-state NMR. Nat Commun 7:1-9

8. Awano T, Takabe K, Fujita M (2001) Xylan and lignin deposition on the secondary wall of Fagus crenata fibers. Prog Biotechnol 18:137-142

9. Vian B, Roland J-C, Reis D, Mosiniak M (2014) Distribution and possible morphogenetic role of the xylans within the secondary vessel wall of linden wood. IAWA J 13:269-282

10. Terrett OM, Lyczakowski JJ, Yu L, luga D, Franks WT, Brown SP, Dupree R, Dupree P (2019) Molecular architecture of softwood revealed by solidstate NMR. Nat Commun 10:4978

11. Yang $H$, Yan $R$, Chen $H$, Lee $D H$, Zheng C (2007) Characteristics of hemicellulose, cellulose and lignin pyrolysis. Fuel 86:1781-1788

12. Yang $H$, Yan $R$, Chen $H$, Zheng C, Lee DH, Liang DT (2006) In-depth investigation of biomass pyrolysis based on three major components: hemicellulose, cellulose and lignin. Energy Fuels 20:388-393

13. Shen DK, Gu S, Bridgwater AV (2010) The thermal performance of the polysaccharides extracted from hardwood: cellulose and hemicellulose. Carbohydr Polym 82:39-45

14. Shen DK, Gu S, Bridgwater AV (2010) Study on the pyrolytic behaviour of xylan-based hemicellulose using TG-FTIR and Py-GC-FTIR. J Anal Appl Pyrolysis 87:199-206

15. Werner K, Pommer L, Broström M (2014) Thermal decomposition of hemicelluloses. J Anal Appl Pyrolysis 110:130-137

16. Wang S, Ru B, Lin H, Luo Z (2013) Degradation mechanism of monosaccharides and xylan under pyrolytic conditions with theoretic modeling on the energy profiles. Bioresour Technol 143:378-383

17. Wang S, Ru B, Lin H, Sun W (2015) Pyrolysis behaviors of four O-acetylpreserved hemicelluloses isolated from hardwoods and softwoods. Fuel 150:243-251

18. Shafizadeh F, McGinnis GD, Philpot CW (1972) Thermal degradation of xylan and related model compounds. Carbohydr Res 25:23-33
19. Wang J, Minami E, Kawamoto $H$ (2020) Thermal reactivity of hemicellulose and cellulose in cedar and beech wood cell walls. J Wood Sci 66:41

20. Wang J, Asmadi M, Kawamoto H (2018) The effect of uronic acid moieties on xylan pyrolysis. J Anal Appl Pyrolysis 136:215-221

21. Asmadi M, Kawamoto H, Saka S (2017) Characteristics of softwood and hardwood pyrolysis in an ampoule reactor. J Anal Appl Pyrolysis 124:523-535

22. Du X, Pérez-Boada M, Fernández C, Rencoret J, del Río JC, JiménezBarbero J, Li J, Gutiérrez A, Martínez AT (2014) Analysis of lignin-carbohydrate and lignin-lignin linkages after hydrolase treatment of xylan-lignin, glucomannan-lignin and glucan-lignin complexes from spruce wood. Planta 239:1079-1090

23. Balakshin M, Capanema E, Gracz H, Chang H, Jameel H (2011) Quantification of lignin-carbohydrate linkages with high-resolution NMR spectroscopy. Planta 233:1097-1110

24. Tarasov D, Leitch M, Fatehi P (2018) Lignin-carbohydrate complexes: properties, applications, analyses, and methods of extraction: a review. Biotechnol Biofuels 11:1-28

25. Hosoya T, Kawamoto H, Saka S (2007) Influence of inorganic matter on wood pyrolysis at gasification temperature. J Wood Sci 53:351-357

26. Asmadi M, Kawamoto H, Saka S (2010) Pyrolysis reactions of Japanese cedar and Japanese beech woods in a closed ampoule reactor. J Wood Sci 56:319-330

27. Harris JF. Baker AJ, Conner AH. Jeffries TW. Minor JL, Pettersen RC, Scott RW, Springer EL, Wegner TH, Zerbe JI (1985) Two-stage, dilute sulfuric acid hydrolysis of wood: an investigation of fundamentals. General Technical Reports. FPL-45. Madison, WI: U.S. Department of Agriculture, Forest Service, Forest Products Laboratory, $73 \mathrm{p}$.

28. Bertaud F, Sundberg A, Holmbom B (2002) Evaluation of acid methanolysis for analysis of wood hemicelluloses and pectins. Carbohydr Polym 48:319-324

29. Bleton J, Mejanelle P, Sansoulet J, Goursaud S, Tchapla A (1996) Characterization of neutral sugars and uronic acids after methanolysis and trimethylsilylation for recognition of plant gums. J Chromatogr A 720:27-49

30. Li J, Kisara K, Danielsson S, Lindström ME, Gellerstedt G (2007) An improved methodology for the quantification of uronic acid units in xylans and other polysaccharides. Carbohydr Res 342:1442-1449

31. Sundberg A, Sundberg K, Lillandt C, Holmbom B (1996) Determination of hemicelluloses and pectins in wood and pulp fibres by acid methanolysis and gas chromatography. Nord Pulp Pap Res J 11:216-219

32. Mejanelle P, Bleton J, Tchapla A, Goursaud S (2002) Chapter 24 Gas chromatography-mass spectrometric analysis of monosaccharides after methanolysis and trimethylsilylation. Potential for the characterization of substances of vegetal origin: application to the study of museum objects. J Chromatogr Libr 66:845-902

33. Timell TE (1967) Recent progress in the chemistry of wood hemicelluloses. Wood Sci Technol 1:45-70

34. Tyminski A, Timell TE (1960) The Constitution of a glucomannan from white spruce (Picea glauca). J Am Chem Soc 82:2823-2827

35. Kawamoto H (2017) Lignin pyrolysis reactions. J Wood Sci 63:117-132

36. Wang S, Wang K, Liu Q, Gu Y, Luo Z, Cen K, Fransson T (2009) Comparison of the pyrolysis behavior of lignins from different tree species. Biotechnol Adv 27:562-567

37. Asmadi M, Kawamoto H, Saka S (2011) Gas- and solid/liquid-phase reactions during pyrolysis of softwood and hardwood lignins. J Anal Appl Pyrolysis 92:417-425

\section{Publisher's Note}

Springer Nature remains neutral with regard to jurisdictional claims in published maps and institutional affiliations. 